\title{
Desenhos e vozes no ensino de geografia: a pluralidade das favelas pelos olhares das crianças
}

Juliana Maddalena Trifilio Dias'

\section{Resumo}

A ciência geográfica prioriza como objeto de estudo as relações entre sociedade e natureza. No entanto, é preciso refletir sobre a possibilidade de escuta no ensino da geografia escolar, em diálogo com sua epistemologia. 0 recorte escolhido para ilustrar a potencialidade dessa perspectiva se deu na busca por compreender a leitura de mundo a partir da favela, considerando-se a pluralidade presente nas produções de sentidos e significados dos sujeitos que a observam. Em tais produções, existem as experiências mediadas e aquelas diretas com as/nas favelas. Quais noções, entretanto, orientam a concepção de favelas construídas pelos alunos? Compreender como os alunos percebem as favelas e criam sentidos e significados ao conceberem suas noções foi uma importante aproximação entre os saberes escolares e não escolares no processo educativo e na aprendizagem espacial. A pesquisa desenvolvida aponta a geografia humanista como uma possibilidade de compreensão do universo investigativo na contemporaneidade, ao permitir deslocar diferentes sentidos - no caso, do espaço urbano e de suas relações com o ensino - para escorar ações de formação de professores. Repensar noções como espaço e lugar propicia a reflexão sobre a apropriação de diferentes sentidos e saberes na escola e fora dela. 0 espaço urbano está repleto de práticas sociais que revelam diversas temporalidades e experiências espaciais. Pensá-lo no interior da escola significa dar visibilidade aos diferentes sujeitos e às suas territorialidades. Para alcançar esse objetivo, utilizou-se o desenho infantil como um instrumento de interlocução com os sujeitos.

\section{Palavras-chave}

Ensino de geografia - Geografia humanista - Desenhos de crianças

- Favelas.

I- Universidade Federal de Juiz de Fora, 


\section{Drawings and voices in the teaching of geography: the plurality of favelas through the eyes of children}

Juliana Maddalena Trifilio Dias'

\begin{abstract}
The science of geography prioritizes the relationships between society and nature as an object of study. However, one needs to reflect on the possibility of listening in the teaching of geography in schools, in dialogue with its epistemology. The outline chosen to illustrate the potential of this approach results from the quest to understand the reading of the world from the favela, considering the plurality present in the productions of senses and meanings of the subjects who observe it. In such productions, there are mediated experience and direct experience with/in favelas. What notions guide the concept of favelas constructed by students, though? Understanding how students perceive favelas and create senses and meanings when conceiving their notions was an important connection between school and non-school knowledge in the educational process and spatial learning. This study points to humanistic geography as a possibility of understanding the investigative universe in contemporaneity, by allowing to shift various meanings - in this case, of urban space and its relations with teaching - to shore up teacher education actions. Rethinking notions such as space and place provides a reflection on the appropriation of different meanings and knowledge in school and beyond. Urban space is filled with social practices that reveal different temporalities and spatial experiences. Thinking it within the school means giving visibility to different subjects and their territorialities. To achieve this goal, this study used children's drawings as a tool for dialogue with the subjects.
\end{abstract}

\section{Keywords}

Teaching of geography - Humanistic geography - Children's drawings - Favelas.
I- Universidade Federal de Juiz de Fora, Juiz de Fora, MG, Brasil. Contact: juliana.maddalena@uff.edu.br 
A pesquisa desenvolvida aponta a geografia humanista como uma possibilidade de compreensão do universo investigativo na contemporaneidade, ao permitir deslocar diferentes sentidos - no caso, do espaço urbano e de suas relações com o ensino - para escorar ações de formação de professores. Repensar noções como espaço e lugar propicia a reflexão sobre a apropriação de diferentes sentidos e saberes na escola e fora dela. 0 cenário do espaço urbano está posto e repleto de práticas sociais que revelam diversas temporalidades e experiências espaciais. Pensá-lo no interior da escola significa dar visibilidade aos diferentes sujeitos e suas territorialidades.

Nesse contexto, as transformações políticas, econômicas, sociais e culturais de nosso tempo desafiam o espaço da educação diante das novas formas de produção e aquisição de conhecimento na sociedade contemporânea. Para interpretar e responder ao que afeta a construção das subjetividades dos estudantes, precisamos nos apropriar de outros saberes e modos de interpretar a realidade. No campo do pensamento geográfico, uma corrente se apresenta como marca referencial para esta pesquisa.

A geografia humanista é apresentada por seus autores como aquela que dialoga com diferentes campos, como psicologia, antropologia, filosofia, arquitetura, educação e outros. Segundo Christofoletti (1982), sua base apresenta grandes nomes, tais como Yi-Fu Tuan, Anne Buttimer, Edward Relph e Mercer e Powell, valorizando a experiência vivida do indivíduo. Nesta pesquisa, deter-me-ei nas noções de Yi$\mathrm{Fu}$ Tuan e em sua distinção entre espaço e lugar a partir da análise de desenhos. Suas noções não são de uso exclusivo dessa temática e podem dialogar com diferentes campos.

0 debate sobre imagens no ensino de geografia pode ser lido a partir da interseção de grandes campos: da epistemologia da geografia, da educação e de suas consequências na formação de professores. Esse intercruzar temático, atravessado pela leitura de imagens, revela um fio entre questões nascidas da prática da sala de aula, a busca por um mergulho teórico ancorado na epistemologia da ciência geográfica e o anseio por pensar a formação de professores para além de conteúdos escolarizados.

É comum a associação dessa disciplina a aspectos como a memorização de pontos localizáveis em mapas, a descrição de elementos naturais da paisagem, a ideia de relatos e exibições de imagens de turismo em diferentes partes do mundo ou, ainda, a tentativa de explicar catástrofes ambientais. Pensando na relação dos sujeitos com seus saberes, quais são aqueles que os estudantes carregam em sua trajetória? Quais geografias têm configurado os saberes escolares?

Segundo Gauthier et al. (1998), os possíveis saberes relacionados à prática escolar são os disciplinares, os curriculares, os da ciência da educação, os da tradição pedagógica, os experienciais e os da ação pedagógica. Eles funcionam como um reservatório organizado pelo professor ao longo de sua formação e de sua prática. Compartilhando desse raciocínio, Tardif (2008) nos apresenta questões que se somam às de Gauthier: quais são os saberes que servem de base para a aprendizagem do aluno? Como o aluno os adquire? Quais ele utiliza? 0 autor ainda enfatiza que os saberes dos professores parecem estar assentados em transações constantes entre o que eles são e fazem num dado contexto. Charlot (2005) compartilha da ideia de que o docente é um sujeito que carrega saberes e que não se separa deles ao ingressar em uma instituição escolar. 0 mesmo ocorre com os estudantes que levam consigo saberes escolarizados e não escolarizados, e, portanto, pensar nesses saberes e em suas mediações é considerar, efetivamente, essas pluralidades e transformações pertinentes aos sujeitos envolvidos no cotidiano escolar.

Os estudantes, ao cursarem a escola básica, carregam conhecimentos decorrentes de suas vivências espaciais, de suas experiências, resultados de seus deslocamentos, de suas moradias e de sua convivência com diferentes pessoas e grupos sociais. Além da experiência 
direta, podemos considerar aquelas mediadas por outras pessoas, pela fotografia, pelos livros, pelo cinema, pelos telejornais, pelas novelas e por outras formas. Como essas informações dialogam com os saberes escolarizados?

0 ensino da Geografia certamente deve deter-se nessa nova cultura imagética, na tentativa de desenvolver uma pedagogia preocupada com a leitura das imagens [...]. Desse modo, é possivel encontrar outra ampla dimensão educativa, outro campo de constituição de sujeitos muito úteis nas nossas práticas pedagógicas. (TONINI, 2003, p. 35)

0 campo ocupado pela imagem na contemporaneidade se desponta a cada compartilhamento via internet. Sua força na constituição dos significados sobre o mundo afırma e reafirma a fabricação de nossas subjetividades. 0 campo imagético está presente nas atividades escolares e também fora da escola.

É certo que essas informações-em-imagens se tornam parte integrante do banco de imagens de que nos utilizamos para mover-nos no mundo, para pensá-lo. Provavelmente, muitos duvidarão do contexto midiático ou da pessoa que mostrou a imagem, fazendo com que esta fique sob suspeita. Não propriamente a imagem, mas a localização dela no discurso acerca do espaço, a localização dela na realidade espacial do planeta. (OLIVEIRA JR., 2009, p. 21)

0 volume e a densidade do campo imagético atuam hoje no modo como vemos o mundo, como nele nos posicionamos e como tecemos nossas relações espaciais. Esta pesquisa procurou a aproximação com as imagens para que, a partir delas, fosse possível um entendimento do processo entre experiência espacial, leitura de mundo e atitude dos sujeitos.

A discussão sobre mediações e experiência na aprendizagem espacial apresentada neste texto nasceu a partir de um diálogo, em sala de aula, com alunos do $6^{\circ}$ ano do ensino fundamental. Ao abordar os fatores de localização industrial, os estudantes foram questionados sobre as prováveis causas que levaram determinada multinacional a escolher uma cidade média e não uma metrópole para sua sede fora de seu país de origem. Foi quando um aluno imediatamente respondeu: "Esta empresa jamais poderia ir para o Rio de Janeiro porque lá ela seria assaltada todos os dias". Perguntei o porquê e ouvi: "Por que lá tem muita favela e tá cheio de bandidos". Depois de alguns instantes lhe perguntei o que era uma favela: "Favela é um aglomerado urbano com o mínimo de 51 habitações..."

0 aluno apresentou uma noção sobre favela que não dialogava com a definição do IBGE, a qual, por sua vez, não se aproximava do processo de favelização que, como professora de geografia, eu pretendia abordar. Qual era o conceito de favela, afinal? Como aquelas noções dialogam com os saberes escolarizados?

A pesquisadora Sonia Miranda (2010, p. 371) afirma:

[...] evoca-se continuamente a necessidade de se compreender melhor de que maneira se constituem, nos sujeitos, os processos que conferem inteligibilidade à informação histórica advinda de dentro e fora da escola. $\mathrm{Na}$ medida em que lidamos com distintos processos sociais e culturais que educam os sujeitos e constituem subjetividades no tocante ao entendimento de elementos próprios da matéria histórica, aquilo que a criança estabelece como parâmetro de entendimento do passado e/ou da mudança assenta-se, muitas vezes, nas relações que se estabelecem entre suas práticas de sociabilidade, os saberes escolarizados, os múltiplos lugares de memória que criam sentidos à moderna experiência do viver no espaço urbano e a indústria cultural que gravita em torno da escola.

A construção realizada pelo aluno sinaliza um movimento interno tecido a partir de sua 
experiência indireta acumulada ao longo do tempo com a cidade carioca. Ele se afeta pelas imagens que tocam seus sentidos e cria significados a partir dessa experiência. A busca pelo entendimento das relações entre esse viver no espaço urbano e estudá-lo na escola revelou a força dessa experiência, direta ou mediada, na constituição dos sujeitos.

Aquele diálogo inicial suscitou algumas questões sobre a aprendizagem espacial das crianças e a temática da favela despontou como uma das possibilidades de análise do espaço urbano. Como elas percebem a favela? Com quais noções sobre favela chegam à escola? A partir de quais referenciais o sujeito elabora sua noção de favela? 0 desejo não foi o de estudar apenas os processos relacionados à favelização. Foi necessário entender e adentrar nesse contexto da criança para explorar sua realidade, em especial, relacionada ao conceito de favelas. Nesse sentido, o foco de investigação deixou de ser a favela e tornou-se o olhar da criança sobre aquele espaço. Esse olhar ilustra a possibilidade de ancoragem de processos educativos a partir do referencial da geografia humanista e do aporte de Yi-Fu Tuan, que podem ser aplicados para além da temática em questão. Assim, este texto pretende transpor uma discussão sobre favelas ou sobre o modo como elas são vistas pelas crianças. Em contrapartida, a favela foi o marco para a pesquisa, que aqui pode ser elucidada por meio dos desenhos das crianças a fim de que possamos refletir sobre possibilidades de inteligibilidade do espaço geográfıco dentro e fora da escola.

A escolha temática recai sobre o ensino do espaço urbano e está diante de um segmento da geografia que confronta, em sala de aula, a vivência diária e a construção de conceitos que podem ser antagônicos à experiência de vida dos alunos. A relevância está nos conflitos entre saberes escolares e não escolares que se encontram num espaço de formação que reúne diferentes sujeitos, percepções do espaço geográfico, sentimentos gerados por experiências com/nos espaços e modos de se posicionar no mundo. Tal importância é manifestada na indicação da geografia humanista para interpretação desses fenômenos inseridos num cenário educativo. Afınal, quais são os olhares e as vozes desses alunos sobre as favelas num processo de aprendizagem espacial?

\section{A geografia humanista diante de um objeto plural}

"Existem tantas geografias quantos forem os métodos de interpretação; existirão tantas quanto forem os posicionamentos sociais existentes" (MORAES, 1986, p. 30). Penso na multiplicidade de geografias e sujeitos presentes nessa frase ao mesmo tempo em que apresento a pesquisa sob a perspectiva de determinada geografia. São inúmeras as discussões sobre o que é a geografia, quais são seus métodos e seu objeto, bem como sobre as dualidades que essa ciência carrega: geral e/ou regional; física e/ou humana; universal e/ou singular; acadêmica e/ ou escolar. A partir dessas dualidades, não há como negar, hoje, que existe uma interpretação do espaço feita pelo indivíduo. Nesse sentido, a geografia humanista se apresenta como um campo de possibilidades de valorização das experiências do sujeito na percepção espacial.

De acordo com Christofoletti (1982), a geografia humanística ${ }^{1}$ procura valorizar a experiência do indivíduo ou do grupo a fim de compreender o comportamento e as maneiras de sentir das pessoas em relação aos seus lugares. Trata-se de olhar para o indivíduo, para suas atitudes, para sua relação com o lugar, em uma aproximação não apenas do espaço, e sim de seus sujeitos.

Holzer (2003) indica que, para o geógrafo Yi-Fu Tuan, a percepção do espaço é orientada pelo corpo humano aliado às categorias temporais, de modo que o sujeito compreende o espaço no presente a partir de sua formação passada e tem sua atitude orientada ao futuro com essa experiência vivida.

1- Geografia humanística é a expressão utilizada por alguns autores, como Antonio Christofoletti, para designar a geografia humanista. 
Investigados os diversos significados de espaço, Tuan iria se dedicar ao lugar. Ele observa que o lugar, na linguagem coloquial, tem dois significados: posição na sociedade e localização espacial. Mas, além destes, tem outro mais profundo: ele possui ' espírito', 'personalidade', existe um 'sentido do lugar'. Este sentido remete-se à apreciação visual ou estética, e também pela audição, olfato, paladar e tato, que exigem um contato próximo e uma longa associação com o ambiente. (HOLZER, 2003, p. 120)

Por meio da geografia humanista, Yi-Fu Tuan valoriza a integração espacial mais pela dimensão afetiva do que pela métrica. Holzer (2003, p. 121) registra que Tuan "caracteriza o lugar a partir da experiência. 0 lugar era avaliado como lar, em suas diversas escalas: o próprio lar, a vizinhança, a cidade, a região e ao estado-nação". Nesse sentido, como cita o autor, a experiência se dá ao conhecermos o mundo via sensação (e sentimento), percepção e concepção. A investigação desta pesquisa se pautou em compreender essas experiências das crianças com base nos sentidos despertados a partir das favelas.

No instante em que o eu do sujeito, o outro e o meio estão inter-relacionados, para caminharmos no pensamento de Yi-Fu Tuan, é preciso pontuar algumas palavras-chave que, segundo o autor, estão interligadas e levam ao entendimento de seu conceito principal: topofilia.

0 primeiro vocábulo a ser compreendido é o que caracteriza essa corrente da geografia: a percepção. Para o geógrafo,

[...] percepção é tanto a resposta de sentidos aos estímulos externos, como a atividade proposital, na qual certos fenômenos são claramente registrados, enquanto outros retrocedem para a sombra ou são bloqueados. (TUAN, 1980, p. 4)

0 foco dessa afırmação está na relação com os sentidos humanos. Dessa forma, o sujeito percebe no espaço determinados elementos e outros não. E como ele sente a partir daquilo que percebe? Para essa noção de percepção, é adotada a ideia do que está ligado aos sentidos, aos registros de memória e ao ato de lembrar ou esquecer os lugares.

Se essa percepção mexe e afeta o indivíduo, o que ele faz com seus sentidos? A atitude seria a próxima palavra. De acordo com o autor,

[...] atitude é primariamente uma postura cultural, uma posição que se toma frente ao mundo. As atitudes implicam experiência e certa firmeza de interesse e valor. (TUAN, 1980, p. 14)

Para conhecer o olhar pontual de uma criança, é necessário identificar o que permeia sua atitude, sua postura ao falar e ao desenhar sua noção de favela. Ou seja, os valores históricos, sociais e culturais que perpassam as esferas de relações dessas crianças.

A partir da noção dos vocábulos que norteiam a construção conceitual de Tuan (1980, p. 4-5), é possível compreender o sentido da utilização do grande termo topofilia: “Topofilia é o elo afetivo entre a pessoa e o lugar ou ambiente físico. Difuso como conceito, vívido e concreto como experiência pessoal".

Nessa noção de topofilia, a riqueza e a força da experiência pessoal na visão sobre o lugar são valorizadas em detrimento de outras geografias que anulariam tais relações. 0 modo como as experiências do indivíduo interferem em sua percepção sobre determinado lugar é imprescindível na aprendizagem espacial. Para Tuan (1983), a experiência é formada de sentimentos e pensamentos, e essa foi a noção na qual me detive. De acordo com Luciano Castro Lima (2006), nosso corpo é o primeiro meio, não há como ignorá-lo, muito menos nossos sentidos. Trato, dessa forma, de uma geografia que vê, toca, ouve e sente o espaço.

Segundo Tuan $(1980,1982,1983)$, a experiência é um termo que abrange as diferentes maneiras por meio das quais uma pessoa conhece 
e constrói a realidade, passando pelos sentidos, pela simbolização e pelo colorido das emoções, permitindo a interpretação do lugar. Na relação entre espaço e lugar, um não se define sem o outro. Na experiência, o significado de espaço frequentemente se funde com o de lugar. 0 que começa como espaço indiferenciado transforma-se em lugar à medida que o conhecemos melhor e o dotamos de valor. Numa perspectiva em que o sujeito é central na relação espacial com o lugar, quais são os olhares das crianças para as favelas? Como esses olhares, inseridos no processo educativo, podem ser interpretados a partir da geografia humanista?

\section{Desenvolvimento e análise do estudo}

Nesta pesquisa, ${ }^{2}$ buscou-se compreender como as crianças - sujeitos e atores sociais percebem, concebem e apresentam suas noções sobre uma parcela do espaço urbano: as favelas.

Para compreender a relação entre percepção do espaço favela e experiências dos sujeitos com o espaço, foram entrevistados 25 estudantes do $7^{\circ}$ ano do ensino fundamental de uma escola particular ${ }^{3}$ que não são moradores de favelas, com idades entre 11 e 13 anos, e analisados 140 desenhos produzidos por todos os alunos daquela série. Os sujeitos estavam já no final da infância e foram escolhidos devido ao desejo de lhes dar voz por meio da pesquisa nesse cenário urbano em que a favela se insere. Todos os alunos elaboraram os desenhos quando cursavam o $6^{\circ}$ ano, durante as aulas de outro professor que trabalhava a temática. Por circunstância da pesquisa, o professor disponibilizou os trabalhos dos alunos para uso no futuro. As produções ficaram arquivadas e no ano seguinte a pesquisa se desenvolveu na mesma escola.

2- A presente pesquisa integra a dissertação de mestrado intitulada Crianças e favelas: percepções, mediações e sentidos, defendida no Programa de Pós-Graduação em Educação da Universidade Federal de Juiz de Fora (DIAS, 2010).

3- Nesta pesquisa não foram divulgados os nomes da escola, dos alunos e dos professores envolvidos no universo investigativo.
Todos os 140 desenhos foram analisados e tiveram seus dados tabulados a partir de elementos que se repetiam com maior frequência e daqueles que apresentavam suas singularidades. Essa etapa foi desenvolvida apenas entre o olhar do pesquisador e os desenhos a serem observados. Os desenhos não estavam acompanhados das vozes de seus autores, o que aumentou o desejo de ir ao encontro dessas crianças para compreender suas noções de favela.

Ao terem notícia da pesquisa, os alunos se apresentaram espontaneamente para rever seus desenhos e participar das entrevistas. Individualmente, os 25 alunos foram entrevistados de forma semiestruturada com seus desenhos em mãos. Dessa forma, foi possível rever os desenhos que haviam produzido no ano anterior e conversar, inclusive, sobre esse deslocamento temporal entre a elaboração e as entrevistas.

Segundo Vigotski (1994, p. 149), “o desenho é uma linguagem gráfica e que surge tendo base na linguagem verbal". A partir desse ponto de vista, a ideia metodológica foi compreender, por meio dos desenhos, como os alunos concebem a ideia de favela na perspectiva da geografia humanista.

A proposta metodológica não foi levar as crianças diante de uma favela para que a representassem, uma vez que, para Vigotski (1994, p. 149), "elas não desenham o que veem e, sim, o que conhecem". Elas desenham de memória sobre o que sabem das coisas, sem ver, apenas com a imaginação. "Al dibujar, El niño lleva al dibujo todo lo que sabe del objeto o que representa y no sólo lo que vé” (VIGOTSKI, 1987, p. 96). Representam o que sabem sem que necessariamente estejam vendo fisicamente o local. Com isso, os desenhos puderam apresentar o que as crianças sabem sobre as favelas e, desse modo, puderam refletir seus caminhos de apropriação. Assim, os estudantes não apresentaram um mundo inventado, mas sim aquele apropriado com os valores e significados de seus contextos refletidos, em seus traços desenhados. Não foram avaliadas as 
formas das figuras representadas e os desenhos permitiram o início das narrativas das crianças.

A linguagem gráfica dos desenhos foi além do simbolismo visual. Ela serviu como elo na comunicação para uma compreensão ativa do outro e, dessa forma, ajudou a perceber a realidade refletida e refratada no discurso dos sujeitos. A fala, portanto, mediou todo o processo de interdependência entre o pensamento, a linguagem gráfica e a verbal.

\section{Análise dos desenhos e entrevistas}

É importante também dizer que o que é visto e lido numa imagem não está somente nela, mas também. Tanto nós vemos as imagens como elas nos veem e nossa leitura dessas imagens é tanto delas quanto de nós próprios. Ao falar de uma imagem, o aluno fala de si mesmo, revela seu univer- so cultural, seu conjunto de experiências e raciocínios com e no mundo. (OLIVEIRA JR., 2005, p. 3)

Numa leitura silenciosa dos desenhos que antecedeu as entrevistas com os estudantes, foi possível imaginar quais seriam as interseções entre a oralidade e a linguagem gráfica apresentada. Com a análise dos 140 desenhos, alguns elementos foram destacados por suas repetições. Para a maioria dos alunos, a favela está relacionada aos aspectos de moradia e à localização em morros. Contudo, não é exclusivamente o modo como são construídas as habitações que orienta a noção de favela dos alunos. Acompanhando a figura 1, é possível identificar que, além dos itens de moradia, alguns desenhos apresentam símbolos de violência, outros são pautados em aspectos de lazer e há também os que inserem marcos de assistência ou prestação de serviços para aqueles moradores.

Figura 1 - Marcas produzidas

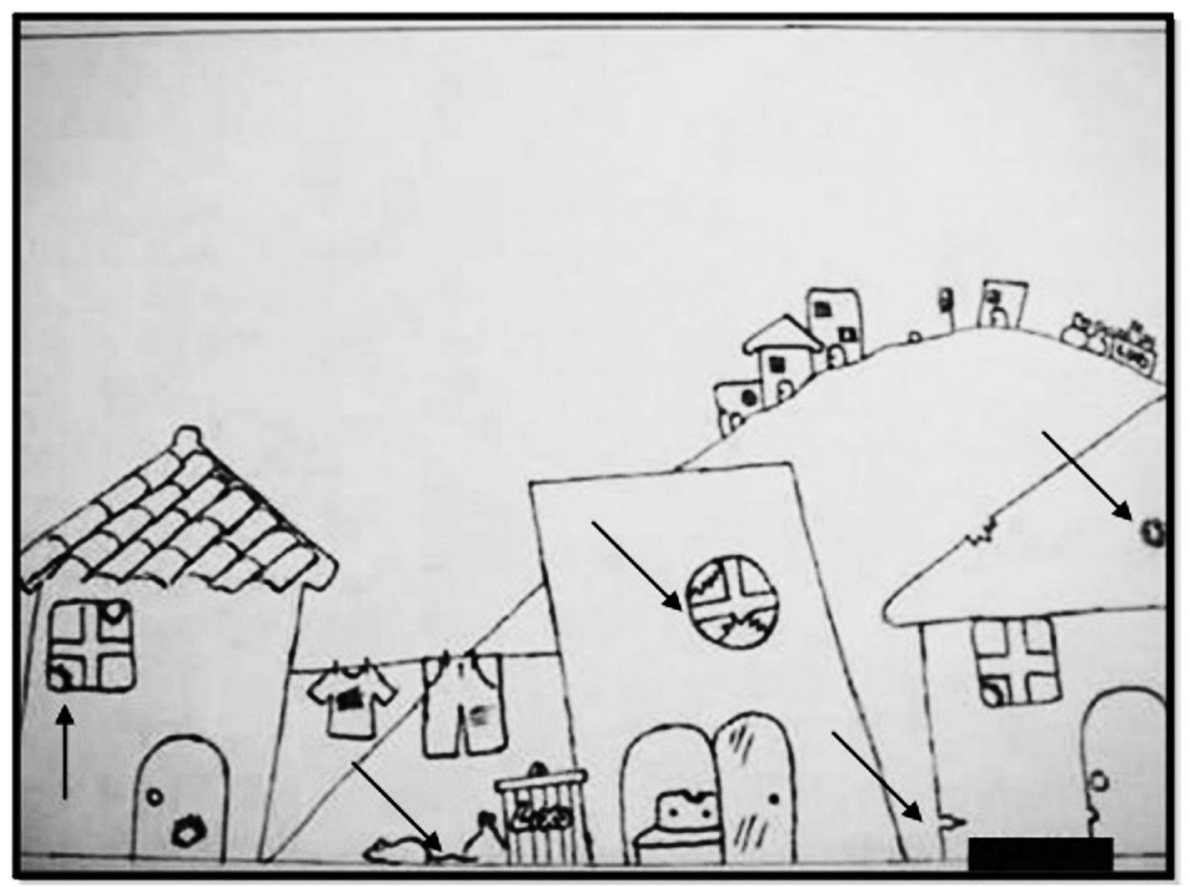

Fonte: Desenho elaborado pelo estudante M4 (fragilidade e marcas de violência nas moradias). 
A fragilidade das construções pode ser observada em sinais como rachaduras, buracos nas paredes, vidros quebrados, tijolos aparentes ou até rabiscos que denunciam alguma forma de abandono ou precária manutenção.

As favelas desenhadas e apresentadas demonstraram algo além dos saberes escolarizados. Elas sinalizaram a força da experiência e das mediações nas construções das noções daqueles espaços, força esta alimentada, principalmente, pelo destaque da mídia televisiva num processo de apresentar imagens aos telespectadores por meio de reportagens, novelas, filmes ou publicidade.

A presença das massas na cidade foi adquirindo pouco a pouco traços mais nítidos. A quantidade de pessoas começou a significar um enorme déficit de habitação e transporte, além de um novo modo de morar na cidade, andar pelas ruas e comportar-se. (MARTINBARBER0, 2008, p. 226)

Essa massa urbana, que por seu volume e sua densidade alterou o modo de ser e agir na cidade, também atravessou a produção cultural e passou a ter como realidade a comunicação em massa. Segundo Martin-Barbero (2008, p. 226), “a massificação era de uma só vez, com mesma força, a integração das classes populares à 'sociedade' e a aceitação por parte desta do direito das massas".

A massificação e a pluralidade de favelas vão ao encontro de uma disciplina de leitura e posicionamento de mundo. Mas como elas têm sido abordadas? Os alunos não se detiveram apenas nos saberes escolares para relatarem suas noções de favelas, mas também em suas experiências indiretas com aqueles espaços, mediadas por outras pessoas e pela grande mídia. Nesse sentido, como o ensino de geografia pode acolher tal pluralidade? Como a epistemologia da ciência geográfica poderia auxiliar na análise de diferentes saberes? Esses saberes não escolarizados têm ecoado nas discussões nas classes? A questão de fundo que atravessa esta pesquisa vai além da escuta das crianças pelos professores e, ao mesmo tempo, permite uma reflexão teórica e metodológica sobre uma ciência tão plural quanto a geografia. Assim, é possível refletir: como compreender a leitura de mundo dos alunos a partir da perspectiva humanista da geografia?

Ao analisar os desenhos, muitos elementos se mostraram naturalizados nas visões apresentadas pelos alunos. Esses elementos podem ser observados na sequência das figuras 2, 3 e 4 .

Figura 2 - Marcas na linguagem

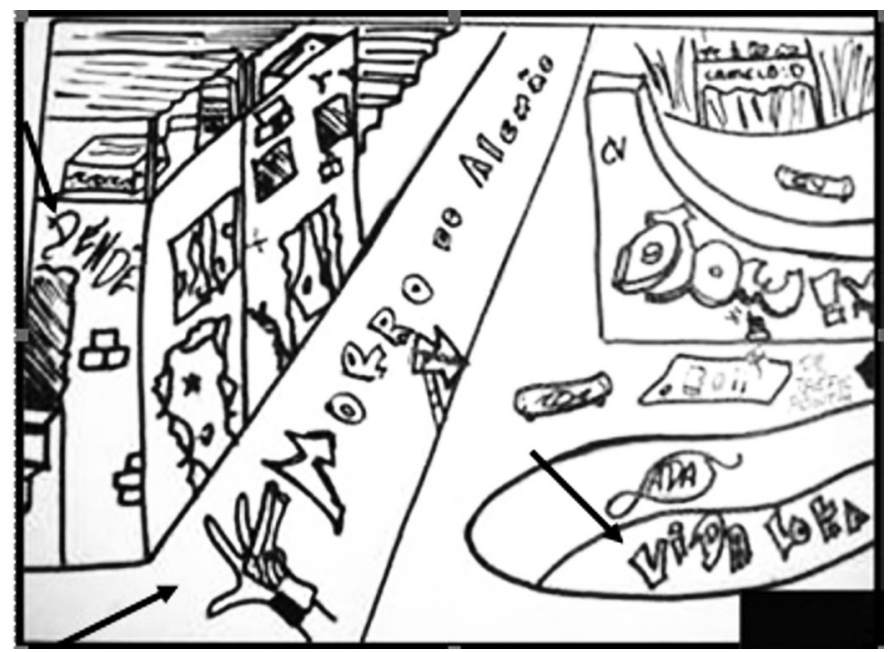

Fonte: Desenho elaborado pelo estudante L3 (violência e alterações na escrita) 
Figura 3 - Manutenção da violência

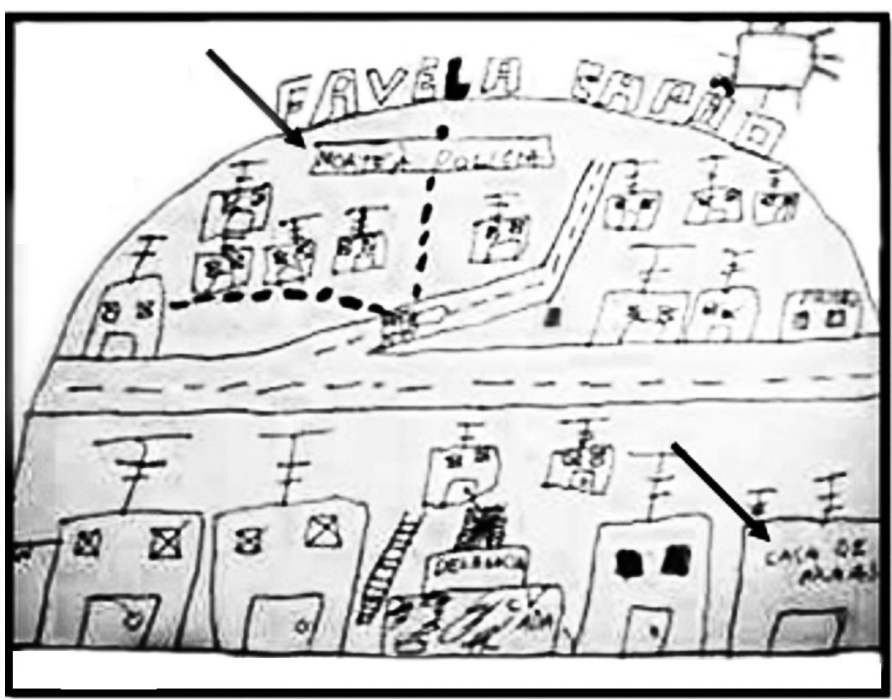

Fonte: Desenho elaborado pelo estudante K1 (marcas de tiros e venda de armas)

Figura 4 - Serviços e lazer

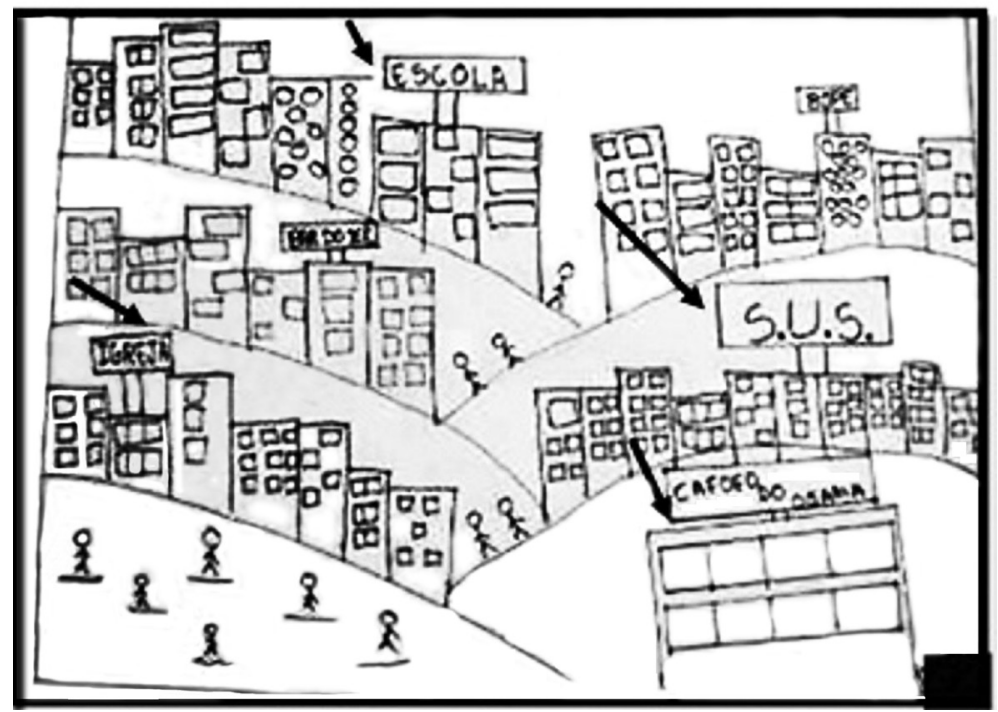

Fonte: Desenho elaborado pelo estudante B1 (prestação de serviços)

Sobre as representações da fragmentação

Casas sem janelas, lajes com churrasco, favelas em morros, pichações com escrita fora da norma da língua, presença de esgoto nas ruas, marcas de tiros nas casas, patrulhas e escassez de serviços públicos se mostraram como elementos cuja repetição demonstra imagens de favelas que os alunos constroem e carregam. do espaço, é possível reler Bauman (2007, p. 90), que aponta as cidades como "espaços em que estranhos ficam e se movimentam em estranha proximidade uns dos outros", num modo do construir o urbano com espaços interditados e destinados aos guetos, voluntários ou não. Com essa forma de estranha proximidade que 
distancia sujeitos, perde-se a necessidade do comprometimento com o outro, na medida em que evitá-lo tornou-se suficiente para o convívio harmonioso. Essa divisão relativa ao convívio harmonioso pode ser vista na figura 5 , que nos apresenta uma via dus ricos.

Figura 5 - Cidade dividida

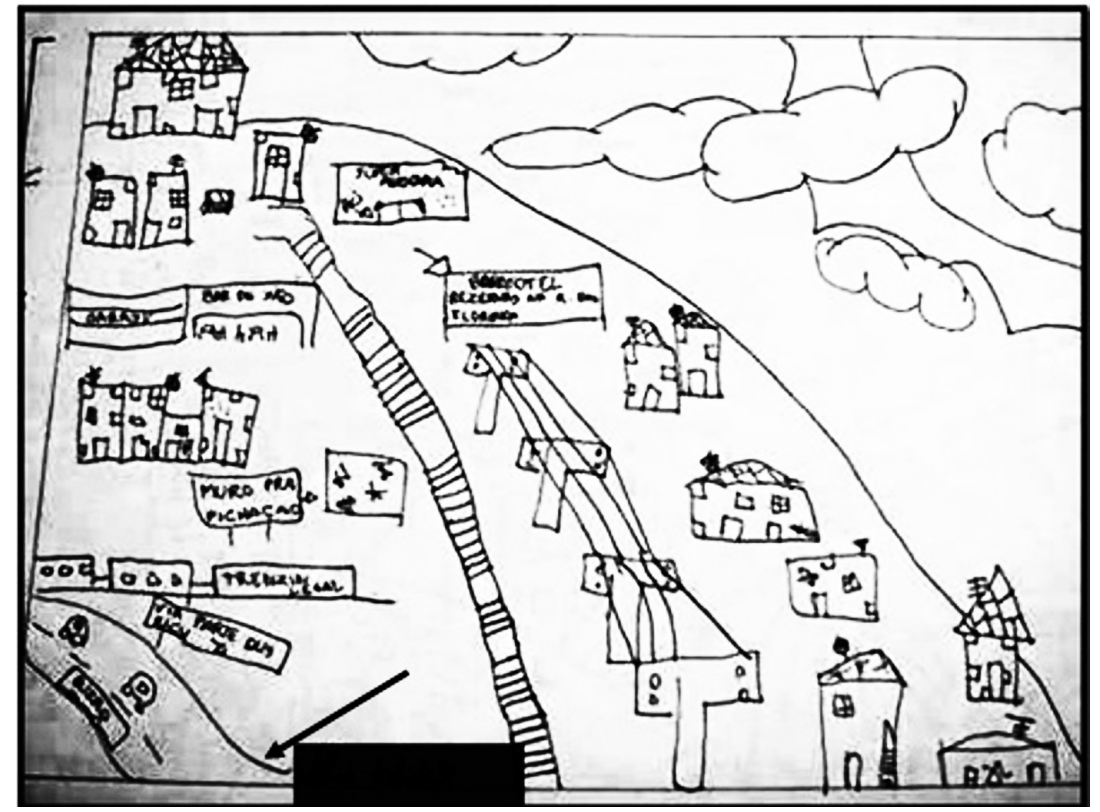

Fonte: Desenho elaborado pelo estudante L6 (via dus ricos)

$\mathrm{Na}$ busca por compreender o campo de experiências dos alunos com as favelas, perguntei-lhes se já haviam visitado alguma delas. Segundo suas respostas, a cidade do Rio de Janeiro tornou-se a principal fonte de observação dos alunos, acompanhada de uma discreta visão de favela na própria cidade situada no interior de Minas Gerais. A relação com a capital fluminense se dá a partir de viagens realizadas pelos alunos e de imagens veiculadas na mídia nacional, o que não necessariamente configura-se numa ida à favela. Se existiu essa noção pela passagem por aquela cidade, também a favela se mostrou aos alunos via televisão e depoimentos de pessoas que lá moram, gerando, assim, a visão de favela de quem passou por ela e a observou, aquelas transmitidas pela mídia e ainda as compartilhadas por alguns moradores.
Perguntei-lhes sobre o que assistiam na TV, e então a programação se diluiu e passou a ser composta por telejornais, filmes e novelas. A interseção entre a programação assistida revela um ponto em comum: a comunicação em massa.

Tais imagens devem ser consideradas como mediadoras de uma experiência que afeta o telespectador e o faz alterar seu modo de apresentar a favela, revelando sua visão de mundo. Assim, a forma como os estudantes veem as favelas incide sobre suas atitudes perante o mundo e, consequentemente, perante as favelas e seus moradores.

Holzer (2003, p. 121) registra que Tuan "caracteriza o lugar a partir da experiência. 0 lugar era avaliado como lar, em suas diversas escalas: o próprio lar, a vizinhança, a cidade, a região e ao estado-nação". Nesse sentido, 
conforme já dito, a experiência se dá ao conhecermos o mundo por meio da sensação, do sentimento, da percepção e da concepção. Todavia, numa releitura dessa definição da década de 1980, podemos considerar, hoje, a força das experiências indiretas ou mediadas que nos permitem conhecer lugares sem que nunca tenhamos viajado até eles.

Com essa noção, evoca-se a ideia de Tuan (1983, p. 10) sobre experiência, na qual me apoiarei: "A experiência está voltada para o mundo exterior. Ver e pensar claramente vai além do eu. 0 sentimento é por alguma coisa e revela a maneira pela qual o 'eu' é afetado". A experiência implica a capacidade de aprender a partir da própria vivência.

A grande mídia desponta, hoje, como propulsora de diferentes experiências espaciais a partir de suas mediações nas experiências dos sujeitos. As novelas, com seus cenários em diversas paisagens do mundo, o telejornal, que busca ir ao local do acontecimento para dar veracidade às suas notícias, e os filmes, que oferecem credibilidade aos espaços que apresentam, são exemplos de como podemos conhecer um local mesmo sem visitá-lo.

As mídias contemporâneas, associadas às corporações que definem hábitos quanto a objetos de desejo, em termos de consumo, têm exercido funções importantes no sentido de funcionar como uma base de produção simbólica a partir do qual as crianças adquirem um sentido de si mesmas. (MIRANDA, 2010, p. 371)

A pluralidade das favelas foi apresentada pelos alunos a partir de seus sentidos e sentimentos por esses lugares. Diante de tantos elementos, muitos puderam ser agrupados por suas afinidades temáticas, como elementos de moradia, os que são visíveis nas favelas, os de serviços, transportes, pessoas, diversão e violência. Suas percepções foram aguçadas por experiências diretas ou mediadas com as favelas. Com essa ideia, ao conversar com algumas pessoas sobre a pesquisa, muitas acreditavam que um sentimento fosse sobressair: o medo da favela.

"Os medos são experimentados por indivíduos e, nesse sentido, são subjetivos; alguns, no entanto, são, sem dúvida, produzidos por um meio ambiente ameaçador" (TUAN, 2005, p. 7). Não discuto tipo de medos ou aspectos psicológicos nesta pesquisa. Todavia, não podia me silenciar diante de desenhos que evidenciavam símbolos de violência, como armas e tiros que se associam àquele sentimento. Houve um grande número de elementos que remetiam as favelas a lugares ameaçadores e geradores de medo. No entanto, curiosamente, ter medo não significou já ter ido a uma favela e lá ter vivido alguma situação que despertasse tal sentimento.

As associações entre medo e favela não foram vistas neste trabalho como fruto de traumas vividos em favelas. 0 que sinalizo é a força desse sentimento no discurso dos alunos, o que me fez considerar o peso de relações estabelecidas com as favelas sem que nunca tenham ido a uma delas. Não caberia mais, nesta pesquisa, ponderar apenas a experiência direta e in loco. A busca passou, então, a se concentrar no entendimento daquilo que gerava ou reforçava a força desse sentimento expressado.

Apesar de não ter sido o único, o medo foi um forte sentimento ligado a uma primeira impressão sobre as favelas. Segundo Zaluar e Alvito (1998), a favela já foi associada ao imaginário urbano como foco dissipador de epidemias; lugar de malandros e da promiscuidade; cenário para bandidos com sua violência, lugar de ausência do Estado.

Nesse aspecto, o primeiro eixo de reflexão focou-se nas imagens e falas que sinalizavam o medo. Os elementos de violência foram apresentados pelos alunos em diversas formas, como pichações que amedrontam - por exemplo, da frase "Hoje te vi, amanhã não te vejo mais" -, imagens de armas, tiros ou cenas de violência entre pessoas, como as demonstradas pela figura 6 .

No entanto, a violência apresentada pelos alunos não foi a única visão presente 
nos desenhos. Os espaços de lazer ganharam destaque entre os entrevistados. Em tudo o que a violência silencia os moradores, o lazer os liberta de seus espaços imediatos, levando-os ao convívio em outros espaços da favela, sejam eles em demonstrações coletivas ou em atividades individuais. Essa possibilidade de diversão é capaz de ressignificar os espaços de violência e é também o viés de atuação de poderes oficiais da sociedade.

Figura 6 - Marcas da violência

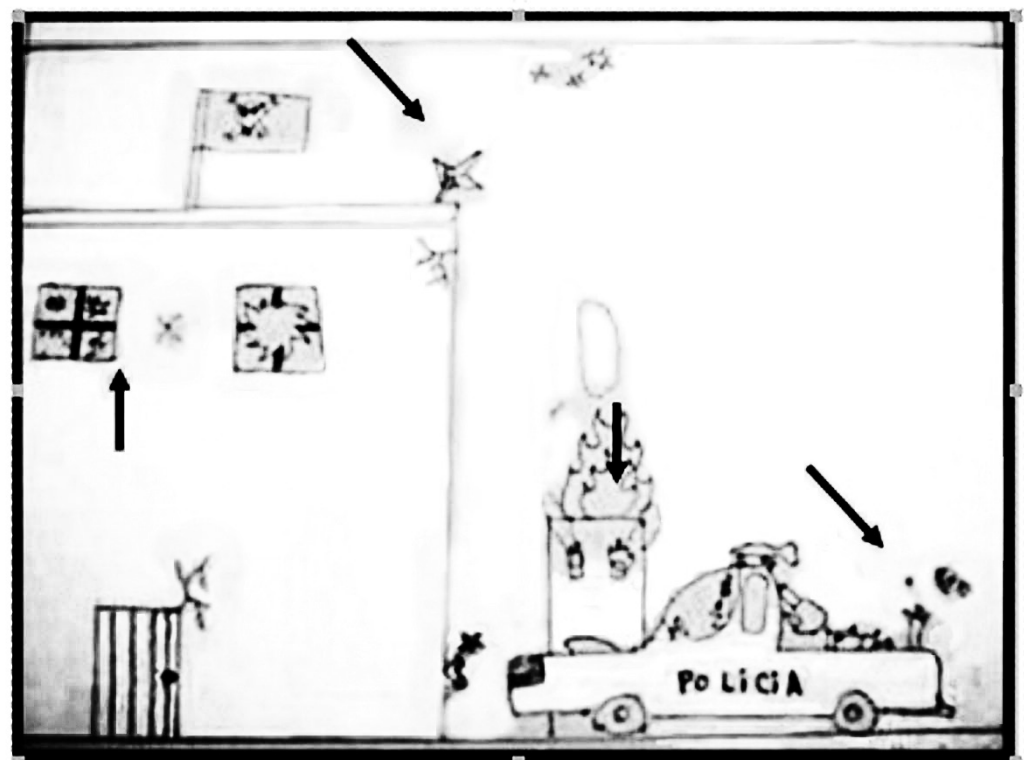

Fonte: Desenho elaborado pelo estudante C1 (confronto armado)

Figura 7 - Lazer privado

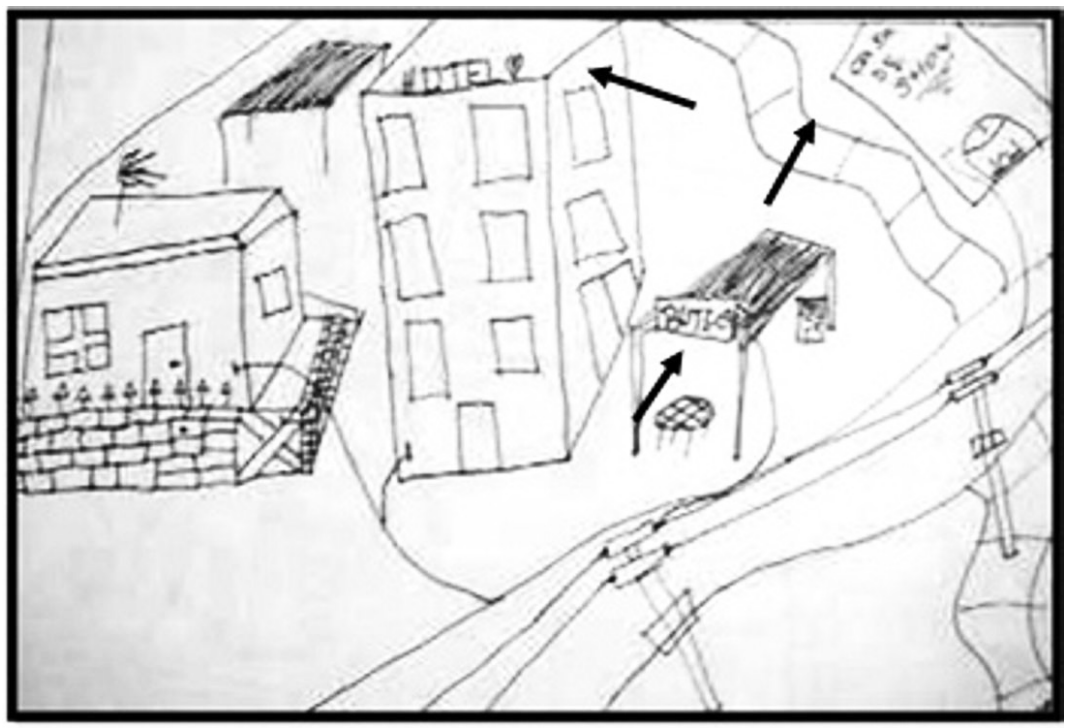

Fonte: Desenho elaborado pelo estudante 01 (hotel, bares e boates) 
O segundo eixo de análise se apoiou nas ocorrências mais significativas referentes aos lugares representados como pontos de lazer na favela. A maioria dos elementos está concentrada entre bares, bailes e boates, seguidos de campos de futebol, igrejas e pipas (vide figuras 7 e 8). Logo após, foram repetidos elementos como bicicletas, skates, hotéis e motéis.

Figura 8 - Lazer gratuito

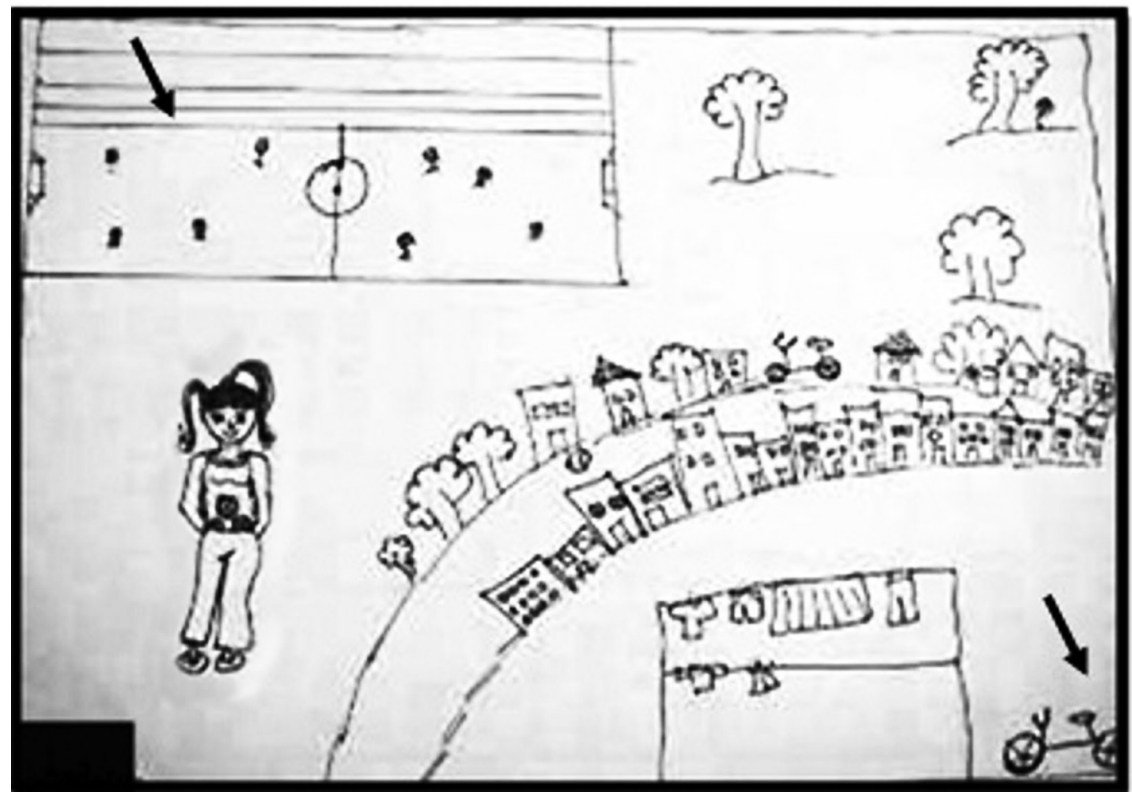

Fonte: Desenho elaborado pelo estudante A2 (locais públicos e elementos de lazer)

Os trechos a seguir revelam essas visões dos alunos. ${ }^{4}$

Pesquisadora: 0 que são esses balões de diálogos no seu desenho?

M15 (aluno): É, porque eu tenho uma noção de que esse pessoal da favela, eles são muito agitados, gostam de funk, aí como era no momento assim... eu desenhei. Eu coloquei como se fossem eles cantando, como se fosse uma festa na laje. Como se fosse uma laje e eles fazendo um churrasquinho... uma festa assim...Pesquisadora: E como que você acha que deve ser o barulho da favela?

M1: Ah, eu acho que final de semana, assim... eles se reúnem, fazem festa,

4- Os trechos das entrevistas foram transcritos de forma literal, respeitando a forma como os diálogos ocorreram.

5- As siglas representam os nomes dos alunos. shows... fazem churrasco entre eles. Sabe? Deve ser muito legal chegar no final de semana e ter um churrasquinho com os amigos, os vizinhos. Ah, quando eu penso em favela, imagino diversão, o pessoal vem no final de semana, aí fica todo mundo conversando.

Pesquisadora: E como imagina que é a vida na favela?

T2 (aluno): Imagino que a vida seja harmoniosa, porque as pessoas, a vizinhança é muito forte na comunidade aí as pessoas têm um pouco mais de companhia. Mas na favela o problema mesmo é o tráfico, e a comunidade ajuda a acalmar isso. Eu sinto que nessas comunidades tem muita união nas famílias... Eu acho legal. Normalmente, as pessoas que passam mais dificuldades são mais unidas com a família do que as que não têm dificuldade... 
Nessa possibilidade de saírem de suas realidades de não moradores de favelas e irem ao encontro desse outro, um sentimento foi fortemente associado à imaginação dos alunos e às suas percepções acerca do cotidiano naquele espaço.

Inúmeras vezes o vocábulo alegria foi repetido nas entrevistas e em suas demonstrações nos desenhos. Os alunos acreditam que as favelas sejam espaços de alegria, convivência e diversão. E todas as vezes que assim se referiam, deixavam clara a ideia atravessada pela imagem de pessoas que se reúnem para se divertir, algo que, segundo alguns alunos, seria o ideal em suas vidas, em que estão ladeados por vizinhos que não se falam. Essa admiração se tornou uma forma de aproximação de realidades geográficas distintas e sinalizou percepções que vão além daquelas apresentadas pelas reportagens discutidas pelos alunos.

Imaginar que os vizinhos se reúnem em churrascos abertos à comunidade, em que as pessoas cantam em suas casas e as crianças brincam nas ruas, foi o modo que os alunos encontraram para descrever a alegria vivida no cotidiano das favelas, conforme retrata a figura 9. Esse modo de compartilhar espaços e vivências pelos moradores nas favelas se apresentou como um grande atrativo aos alunos e como um elemento unificador de suas realidades distantes. As falas sinalizavam que, por muitos momentos, desejavam viver essa dinâmica em suas vidas.

Figura $\mathbf{9}$ - Favela como convite

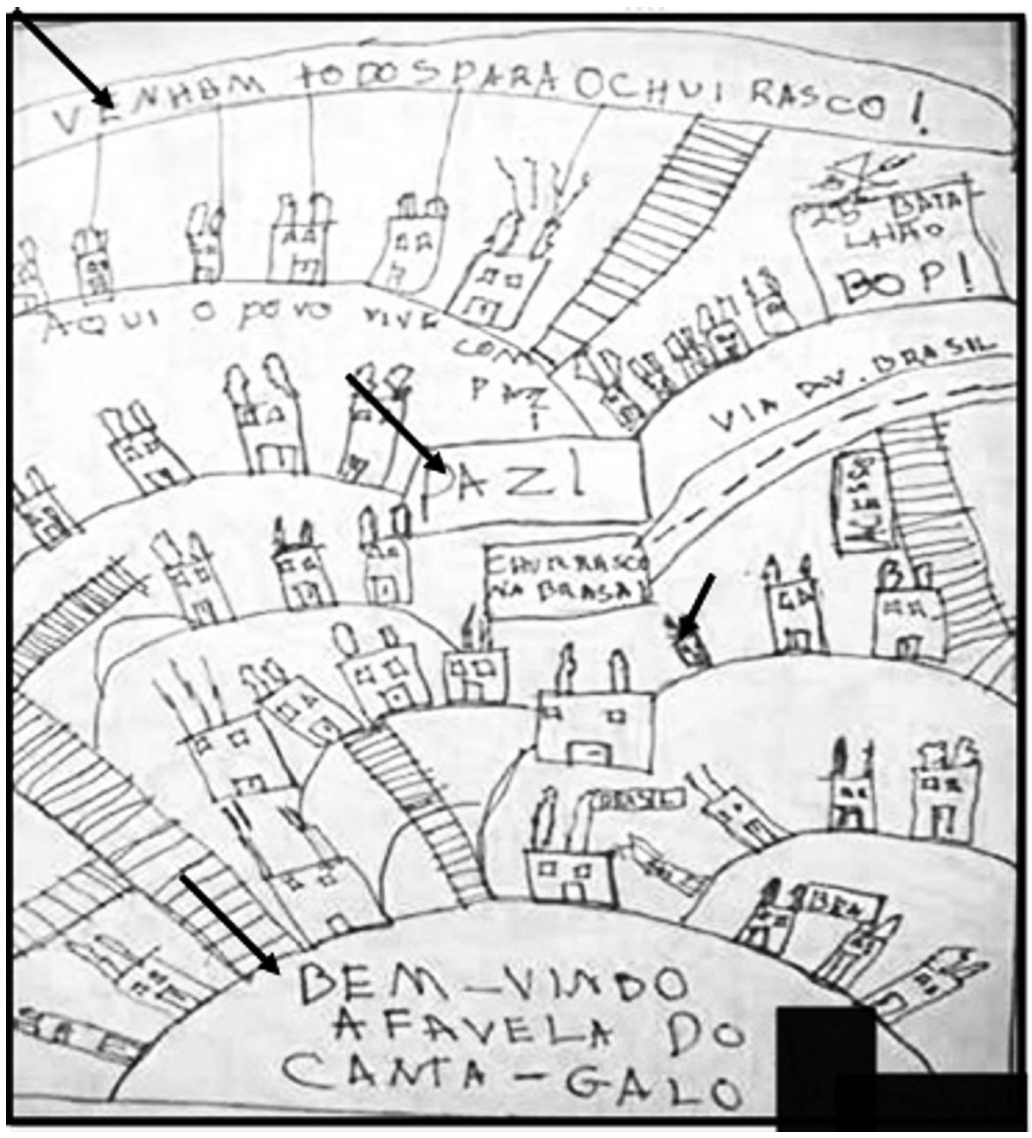

Fonte: Desenho elaborado pelo estudante Y1 (convite, paz e churrasco para todos) 
Para Tuan (1980, 1983), a percepção dos espaços e lugares leva os sujeitos à reflexão e às suas visões de mundo. Tal visão, por sua vez, impulsiona-os a uma atitude de acordo com as referidas percepções. 0 modo como o autor lê o mundo pôde ser entendido a partir do que essa percepção de alegria gerou nos alunos. Esse sentimento, com um misto de admiração, levou os entrevistados a ponderarem as imagens assistidas de violência e a traçarem possíveis planos de ação em suas vidas. Nesse sentido, a supremacia da violência foi colocada em dúvida diante de sentimentos também trazidos pelos estudantes. Suas dúvidas sinalizaram essa capacidade de leitura do mundo, inclusive das fortes mediações que relataram. 0 ato de duvidar que as favelas sejam tão ruins e violentas como são apresentadas gerou uma nova possibilidade: ir ao encontro do outro na favela.

A atitude pretendida reflete a intenção dos alunos de perceberem in loco aquilo que para eles seria viver numa favela. Eles acreditam que assim poderão ponderar se a favela se aproxima mais daquilo que imaginam ou daquilo a que assistem. Independentemente desse contraponto, o que orienta tal pensamento é a vontade do aluno de se colocar como protagonista em suas reflexões e ações. 0 desejo de ir a esses encontros revelou noções que transcenderam a curiosidade pelo local e caminham no sentido de uma ação protagonista.

Se o lugar permite a variação de sentimentos e atitudes, é real valorizar a possibilidade de olhar para o espaço que continua posto, cartografado, localizável, com distância entre dois pontos, mas também com aquilo que nele acontece, que o faz variar pelo modo como o sujeito o percebe. Um espaço que admite o olhar do sujeito ao partir das dimensões corporais, invadir seu intelecto e impulsionar seu comportamento sobre o espaço. É o que podemos reafirmar com base no pensamento de Yi-Fu Tuan sobre percepção, visão de mundo, atitude.

O lugar é a base da reprodução da vida e pode ser analisado pela tríade habitante- -identidade-lugar. É o espaço passível de ser sentido, pensado, apropriado e vivido através do corpo. (CARLOS, 1996, p. 22)

Compartilhando dessa ideia, Ana Fani Carlos (1996) também pondera que o homem percebe o mundo por meio de seu corpo e de seus sentidos. A partir da geografia humanista, a criança pode não ter ido à favela, mas pode ter elementos sensoriais que lhe permitem uma visão daquele lugar e, dessa forma, uma atitude para com ele.

0 raciocínio exposto pelos alunos foi: se eles vivem numa classe favorecida economicamente, estudam as desigualdades sociais e as percebem nas cidades, logo devem fazer algo para minimizar tal desigualdade ou para ajudar aqueles que são vistos como desfavorecidos. Essa é uma visão de quem está de fora de determinada realidade e nela tem vontade de se inserir a partir da ajuda às pessoas. Nesse sentido, eles poderiam ajudar quaisquer indivíduos em lugares e situações completamente diferentes das descritas; no entanto, suas percepções e reflexões sobre as favelas os impulsionaram ao próprio ambiente em questão. A favela não se tornou sinônimo de repulsa e fuga para os alunos que lá não moram, como inicialmente o senso comum apontava.

A atitude dos alunos traz diferentes modos de se ressignificar aquilo que pensam sobre favelas. Ela gera experiência direta e pode alterar a concepção espacial. As vozes dos alunos evidenciaram relações entre espaços, lugares e identidades.

Nesse sentido, o terceiro eixo foi o olhar humanizado que os alunos lançaram para o cotidiano na favela. São alunos com realidades socioeconômicas diferentes daquelas dos moradores de favelas, que reconhecem e assumem o medo da violência, ponderam as imagens que os têm orientado, admitem suas influências e refletem sobre a vida daquelas pessoas que deles são distantes.

Y1 (aluno): Favela? Um lugar onde as pessoas ficam na comunidade e gostam de viver sua vida, sempre unidas... 
L1 (aluno): Ah, às vezes, não sei o que é favela, porque igual eu vi na reportagem, que às vezes muita gente pensa que a favela é.... como é... como que fala, só tem traficantes, essas coisas, mas muitas pessoas são honestas e trabalham.

M1 (aluno): Favela? [Silêncio] Ah, quando eu penso em favela, penso em diversão, o pessoal vem no final de semana, conversando... Mas quando tem filme, reportagem, assim... Eu já penso mais em pessoa com arma lá dentro, aí eu já não sei como é... se é esse clima de alegria ou se é essa violência... assim... que a gente vê

A dúvida de M1 é categórica: o aluno não sabe se a favela é o que sente ou aquilo a que assiste. As imagens da televisão têm um impacto na formação dos sujeitos tão intenso que deslocam outros fios formadores. Ao se envolver com as cenas, "uma veracidade se instala, as palavras são sons de uma discussão verdadeira, indiscutivelmente real" (ALMEIDA, 2004, p. 42). Esse tom de verdade atribuído às cenas televisivas ficou claro ao longo das entrevistas quando os alunos admitiam terem conhecido as favelas com base em tais imagens. Além disso, quanto maior a audiência do telejornal no cenário nacional, maior foi a credibilidade das imagens que medeiam suas experiências.

No entanto, os estudantes têm demonstrado algo que vai além de consumir reportagens. Pelas entrelinhas das entrevistas foi possível perceber a existência de uma reflexão acerca das imagens recebidas. Segundo a perspectiva da geografia humanista, essa é uma forma de se posicionar no mundo percebido, ou seja, trata-se de uma reflexão que poderá tender à ação. 0 aluno M1 aponta esse desejo de ação em sua fala apresentada a seguir.

M1 (aluno): Sinto pena, ver as pessoas ali passando por essas situações em termos de conforto... eu tenho vontade de ajudar, sabe? Acho que ainda não tenho idade para ir e fazer alguma coisa e tal... mas tenho essa vontade...
0 protagonismo que os alunos apontam é fruto dos fios formadores que atuam na constituição de seus eus. Tal sujeito é formado a partir das e nas relações que estabelece com outros. Os estudantes se predispõem à interação com os outros (que são da favela) a partir do desejo de aproximação entre realidades socioeconômicas distintas. Logo, se a favela é conhecida por muitas pessoas como o lugar da ausência, existe uma coerência de pensamento em ajudar com aquilo que é presença em outras classes. Os olhares não foram apenas de repulsa àquilo que os amedrontam, mas revelam, em alguns relatos, a vontade de ir ao encontro, por exemplo, para se divertir junto.

Experiência direta. Eis o que os alunos buscam em suas intenções ao contrapor visões de favelas. Um trânsito que, em vez de paralisá-los em seu meio, motivou-os ao encontro do outro. Uma atitude desejada a partir de uma visão de mundo construída pela maneira como se percebe o espaço em questão.

\section{Algumas considerações}

Este artigo apresenta os resultados de uma pesquisa pautada nas percepções de sujeitos sobre as favelas e nos sentidos despertados por meio de experiências mediadas - e, portanto, indiretas - com o espaço favela. Conhecer o que esses estudantes percebem sobre o espaço, como o sentem e a partir de quais mediações estabelecem suas experiências foi fundamental para compreender as noções de favela que eles carregam em suas formações escolares. As reflexões teóricas e metodológicas da pesquisa apontam a geografia humanista como possibilidade de amparar processos educativos sobre o princípio de compreender o eixo que atravessa experiência, percepção, visão de mundo e atitude, neste caso, na aprendizagem espacial.

Considerar múltiplos olhares para o espaço geográfico no ensino de geografia é afirmar um ensino pautado na escuta e, portanto, numa relação dialógica em sala de aula que busca abranger e enfatizar a experiência na 
aprendizagem espacial. Com a discussão sobre espaço e lugar a partir da geografia humanista, é possível admitir o modo diferenciado como o sujeito se relaciona, percebe e concebe sua noção sobre o espaço. Assim, o espaço favela se configurou como cenário para essa possibilidade de olhares dos sujeitos. Diante da compreensão de que geograficamente os alunos continuavam imbuídos de uma análise espacial, foi pertinente substituir o vocábulo favela pelo seu plural - favelas -, numa sinalização da pluralidade desses espaços.

No decorrer da pesquisa, algumas mediações foram destacadas durante as entrevistas, como a família, a escola e os amigos. No entanto, uma delas foi veementemente apresentada e discutida pelos alunos: a mediação pela mídia televisiva. Alexandra Siqueira (2008, p. 1047) discorre sobre a preocupação comum entre pesquisadores do campo mídia e educação com

[...] as mútuas influências entre mídia, educação e democracia, e com seus desdobramentos, que vão das novas formas de ler e escrever, usando linguagens audiovisuais, à investigação do modo como as pessoas conhecem a realidade através da imprensa, da ficção e da publicidade.

Os alunos relataram inúmeras vezes que as imagens de favelas das quais se recordam são aquelas relativas a palcos de violência. Com fugas, perseguições, tiros e mortes, a favela foi descrita como um lugar onde essas cenas se repetem. 0 que se pode constatar é que, além das imagens que vão se consolidando no senso comum, forte também é a ideia de que estas sejam as únicas e verdadeiras imagens das favelas.

A televisão constitui hoje, simultaneamente, o mais sofisticado dispositivo de moldagem e deformação do cotidiano e dos gostos populares e uma das mediações históricas mais expressivas de matrizes narrativas, gestuais e cenográficas do mundo cultural popular. (MARTIN-BARBERO; REY, 2004, p. 26)
Esse dispositivo de moldagem, deformação e apresentação do cotidiano das favelas ao público em massa tem contribuído para uma noção de favela baseada em imagens de violência. Todavia, neste trabalho, elas não demonstraram ser 0 último olhar no modo de se pensar esses espaços. 0 medo não foi relatado pelos alunos como um sentimento único, tampouco como uma barreira intransponível no convívio entre moradores e não moradores de favelas. Ao contrário, o medo suscitou dúvidas em relação à programação assistida e permitiu uma abertura para o encontro com o outro nessas cidades divididas.

A busca investigativa se iniciou com um conceito definido de favela, no entanto, nenhuma conversa revelou que favela é, para os alunos, apenas o conceito escolarizado do IBGE ou de livros didáticos. Com base no aporte de Yi-Fu Tuan, pode-se dizer que as favelas foram definidas pelos estudantes a partir de suas percepções e repletas de experiências por entre espaços e lugares, as quais enriquecem os diálogos no cotidiano escolar. Esta pesquisa aponta para o olhar e a escuta cuidadosa dos estudantes que estão inseridos num mundo que por eles é percebido. Nessa perspectiva, suas posições e seus olhares cabem numa sala de aula em relação dialógica entre os saberes escolarizados e os não escolarizados.

Holzer (1999, p. 69) relata que, para Tuan,

[...] o mundo é um campo de relações estruturado a partir da polaridade entre o eu e o outro, ele é o reino onde a história ocorre, onde encontramos as coisas, os outros e a nós mesmos, e deste ponto de vista deve ser apropriado pela Geografia.

Essa busca por uma apropriação na geografia, a partir de sua corrente humanista, revela um grande potencial de interseções em diferentes campos sob a ótica de compreendermos a relação entre experiênciapercepção-visão de mundo e atitude.

Reis (2012) sinaliza que, por não existir naturalidade para o encontro e o diálogo entre 
saberes escolares e não escolares, é urgente que os processos educativos ofereçam caminhos para que esses encontros favoreçam a apropriação e a reconfiguração dos saberes dos estudantes.

As favelas serviram de cenário para que fosse possivel conhecer o modo como tais sujeitos têm se relacionado com essa parcela do espaço urbano. Não coube a este texto prescrever aos professores de geografia quais seriam os possiveis recortes de análise, mas a favela foi um deles. No entanto, um dos objetivos é evidenciar a força da relação entre sujeitos e experiência na percepção do espaço que deve ser pensada na formação de professores. Conhecer a visão de mundo do aluno e relacioná-la, segundo a geografia humanista, com suas experiências e atitudes indica um caminho no processo educativo que efetivamente coloca em diálogo os saberes escolares e os não escolarizados.

\section{Referências}

ALMEIDA, Milton José de. Imagens e sons: a nova cultura oral. São Paulo: Cortez, 2004.

BAUMAN, Zygmunt. Tempos líquidos. Rio de Janeiro: Jorge Zahar, 2007.

CARLOS, Ana Fani Alessandri. 0 lugar no/do mundo. São Paulo: Hucitec, 1996.

CHARLOT, Bernard. Relação com o saber: formação dos professores e globalização. Porto Alegre: Artmed, 2005.

CHRISTOFOLETTI, Antonio. Perspectivas da geografia. São Paulo: Difel, 1982.

DIAS, Juliana Maddalena. Crianças e favelas: percepções, mediações e sentidos. Dissertação (Mestrado em Educação) Universidade Federal de Juiz de Fora, Juiz de Fora, 2010.

GAUTHIER, Clermont et al. Por uma teoria da pedagogia: pesquisas contemporâneas sobre o saber docente. ljuí: UNIJUI, 1998.

HOLZER, Werther. O lugar na geografia humanista. Revista Território, Rio de Janeiro, ano IV, n. 7, p. 67-78, jul./dez. 1999.

0 conceito de lugar na geografia cultural-humanista: uma contribuição para a Geografia contemporânea. GEOgraphia, Rio de Janeiro, ano V, n. 10, p. 113-123, 2003

LIMA, Luciano Castro. 0 sentido é o meio. In: PONTUHSCHKA, Níbia Nacib; OLIVEIRA, Ariovaldo Umbelino (Orgs.). Geografia em perspectiva. São Paulo: Contexto, 2006. p. 161-174.

MARTIN-BARBER0, Jésus. Dos meios às mediações: comunicação, cultura e hegemonia. 5. ed. Rio de Janeiro: Editora UFRJ, 2008 .

MARTIN-BARBER0, Jésus; REY, Germán. Os exercícios do ver: hegemonia audiovisual e ficção televisiva. 2. ed. São Paulo: Senac São Paulo, 2004.

MIRANDA, Sonia Regina. Estranhos passados encontrados em um museu: a criança e seus olhares sobre 0 tempo desconhecido. Cadernos CEDES, Campinas, v. 30, n. 82, p. 369-382, set./dez. 2010.

MORAES, Antonio Carlos Robert. Geografia: pequena história crítica. 5. ed. São Paulo: Hucitec, 1986.

OLIVEIRA JR., Wenceslao Machado de. A produção da escuta a partir de imagens. In: ENCONTRO NACIONAL DE PRÁTICA DE ENSINO DE GEOGRAFIA, 8., 2005, Dourados. Anais... Dourados, 2005. p. 1-25.

Grafar o espaço, educar os olhos: rumo a geografias menores. Pro-Posições, Campinas, v. 20, n. 3, dez. 2009. 
REIS, Rosemeire. Experiência escolar de jovens/alunos do ensino médio: os sentidos atribuídos à escola e aos estudos. Educação e Pesquisa, São Paulo, v. 38, n. 3, p. 637-652, jul./set. 2012.

SIQUEIRA, Alexandra Bujokas de. Educação para a mídia: da inoculação à preparação. Educação e Sociedade, Campinas, v. 29, n. 105, 1043-1066, set./dez. 2008.

TARDIF, Maurice. Saberes docentes e formação profissional. 9. ed. Petrópolis: Vozes, 2008.

TONINI, Ivaine Maria. Imagens nos livros didáticos de geografia: seus ensinamentos, sua pedagogia. Mercator: revista de geografia da UFC, ano 2, n. 4, p. 35-44, 2003.

TUAN, Yi-Fu. Topofilia: um estudo da percepção, atitudes e valores do meio ambiente. São Paulo: Difel, 1980. . Geografia humanística. In: CHRISTOFOLETTI, Antonio. Perspectivas da geografia. São Paulo: Difel, 1982. p. 143-164. Espaço e lugar: a perspectiva da experiência. Rio Claro: Difel, 1983. Tradução de Lívia de Oliveira.

VIGOTSKI, Lev S. La imaginacion y el arte en la infância. México: Hispanicas, 1987.

A formação social da mente. 5. ed. São Paulo: Martins Fontes, 1994.

ZALUAR, Alba; ALVITO, Marcos (Orgs.). Um século de favela. Rio de Janeiro: Editora Fundação Getúlio Vargas, 1998.

Recebido em: 12.11.2012

Aprovado em: 11.06.2013

Juliana Maddalena Trifilio Dias é professora da área de Prática de Ensino em Geografia na Faculdade de Educação da Universidade Federal de Juiz de Fora. 